\title{
Etude des interactions entre diverses bactéries lactiques thermophiles et mésophiles, en relation avec la fabrication des fromages à pâte cuite
}

\author{
par \\ J.P. ACCOLAS, Monique VEAUX et J. AUCLAIR \\ Station Centrale de Recherches Laitières et de Technologie \\ des Produits Animaux, I.N.R.A. (78) Jouy-en-Josas
}

\section{Introduction}

Les levains de bactéries lactiques thermophiles, utilisés dans la fabrication du Gruyère et de l'Emmental, sont constitués par des cultures mixtes où se trouvent généralement associés Streptococcus thermophilus et divers lactobacilles tels que Lactobacillus helveticus, L. jugurti* et L. lactis. En outre, bien que ce ne soit pas une pratique absolument générale, les fromagers emploient fréquemment des levains de streptocoques lactiques mésophiles, ajoutés au lait de fromagerie soit la veille de la fabrication afin d'obtenir une "maturation " préalable du lait, soit au moment de l'emprésurage en même temps que le levain de bactéries lactiques thermophiles.

On conçoit aisément que les interactions résultant de l'association de ces diverses espèces bactériennes, peuvent jouer un rôle prépondérant au cours de la fabrication du fromage. En particulier, l'acidification active que l'on souhaite obtenir au cours de l'égouttage sous presse du fromage, dépendra dans une large mesure des relations symbiotiques qui s'établiront entre les différentes bactéries présentes. Il est par exemple connu que l'association de Str. thermophilus et des lactobacilles thermophiles se traduit généralement par un effet synergique notable sur l'activité acidifiante. Cet effet a été

* Au cours de ce travail, nous avons utilisé les dénominations correspondant à la nomenclature classique des lactobacilles (voir par exemple Sharpe [17]). Toutefois, les récentes propositions émanant du Comité International de Nomenclature des Lactobacilles conduiront probablement à diverses modifications de la nomenclature actuelle. Par exemple, L. helveticus et L. jugurti, micro-organismes très voisins, seront vraisemblablement réunis sous une dénomination unique. 
observé par Ritter [16], dans le cas de cultures mixtes sur lait soumises à des conditions d'incubation reproduisant celles de la fabrication et de l'égouttage sous presse des fromages à pâte cuite. De même, les bactéries lactiques thermophiles du yoghourt, Str. thermophilus et $L$. bulgaricus, représentent un cas de syntrophie qui a été bien étudié. Pette et Lolkema $[12,13]$, Bautista et al. [3] ont montré qu'en culture mixte sur lait autoclavé, le lactobacille libérait certains acides aminés, par exemple la valine [13] ou l'histidine et la glycine [3], ces acides aminés exerçant un effet stimulant marqué sur la croissance et sur l'activité acidifiante de Str. thermophilus. Plus récemment, Galesloot et al. [4] et Veringa et al. [18] ont observé, en utilisant du lait chauffé à $90^{\circ} \mathrm{C}$, que Str. thermophilus stimulait l'activité acidifiante du lactobacille, cet effet étant lié à l'apparition d'acide formique dans le lait.

Au cours du présent travail nous avons tout d'abord recherché dans quelle mesure des interactions symbiotiques analogues' pouvaient être mises en évidence, soit en associant Str. thermophilus à divers lactobacilles thermophiles, soit en associant les bactéries lactiques thermophiles à divers streptocoques lactiques mésophiles. Nous nous sommes ensuite attachés à déterminer l'origine de l'effet synergique observé, en étudiant l'action des filtrats de culture sur lait de l'une des souches sur les autres souches bactériennes présentes dans la culture mixte. Enfin, nous avons tenté de voir si divers composés tels que les acides aminés, l'acide formique et l'adénine, déjà connus pour exercer dans certaines conditions une action stimulante sur l'activité des diverses bactéries lactiques, pouvaient éventuellement rendre compte des interactions synergiques que nous observions.

\section{Méthodes}

Souches. Les souches de bactéries lactiques étudiées provenaient de la collection du Centre National de Recherches Zootechniques (C.N.R.Z.). Elles comprenaient d'une part des souches de streptocoques lactiques mésophiles : Str. lactis, Str. cremoris, et d'autre part des bactéries lactiques thermophiles : Str. thermophilus, L. helveticus, L. jugurti, L. bulgaricus, L. lactis. Parmi les bactéries lactiques thermophiles utilisées au cours de ce travail, un certain nombre de souches avaient été isolées de "présures naturelles» du Jura.

Les cultures étaient conservées soit à l'état congelé à $-30^{\circ} \mathrm{C}$, soit à l'état lyophilisé. Avant utilisation, les souches étaient repiquées deux à trois fois sur lait tournesolé. Les cultures étaient incubées soit à $22^{\circ} \mathrm{C}$ pendant 15 à $18 \mathrm{~h}$ dans le cas de streptocoques lactiques mésophiles, soit à $37^{\circ} \mathrm{C}$ pendant 15 à $18 \mathrm{~h}$ dans le cas des bactéries lactiques thermophiles.

Traitement THERmique du LAIt. Nous avons utilisé, tout au long de ce travail, du lait reconstitué à partir de lait écrémé sec granulé, exempt d'antibiotiques (Elle-et-Vire), à raison de $10 \mathrm{~g}$ dans $100 \mathrm{ml}$ 
d'eau distillée. Le lait était chauffé à $80^{\circ} \mathrm{C}$ pendant $30 \mathrm{mn}$. Ce chauffage était nécessaire pour éliminer la plus grande partie de la flore de contamination. Pour un certain nombre d'essais, nous avons également utilisé du lait chauffé à l'autoclave à $110^{\circ} \mathrm{C}$ pendant $10 \mathrm{mn}$. Ces deux traitements thermiques sont voisins de ceux qui ont été utilisés par les différents auteurs qui ont étudié les interactions symbiotiques entre les bactéries lactiques. Cela nous a permis de comparer nos résultats à ceux obtenus précédemment.

MESURE DE LA PRODUCTION D'ACIDE. La production d'acide dans le lait par les différentes cultures étudiées, cultures pures ou cultures mixtes, était mesurée à l'aide de soude décinormale, en présence de phénolphtaléine. Elle était exprimée en degrés Dornic*.

Les doses d'ensemencement, les températures d'incubation, variables suivant les essais, seront précisées au cours de l'exposé des résultats.

Dans un certain nombre d'essais, l'évolution de la production d'acide des cultures a été suivie tout au long de la période d'incubation, et les courbes d'acidification correspondantes ont été tracées. Dans d'autres essais, nous avons simplement mesuré la quantité d'acide produite après une durée d'incubation déterminée.

Pour mettre en évidence l'effet stimulant éventuel d'une souche sur une autre souche, nous avons comparé la quantité d'acide produite par la culture mixte à la somme des quantités d'acide produites, dans les mêmes conditions, par chacune des souches cultivées séparément.

TRAITEMENT THERMiQue DES CULTURES. La fabrication des fromages à pâte cuite faisant intervenir un chauffage du caillé à $54-56^{\circ} \mathrm{C}$, nous avons étudié l'influence éventuelle d'un traitement thermique voisin de celui utilisé en technologie (chauffage à $54^{\circ} \mathrm{C}$ pendant $1 \mathrm{~h}$ ) sur l'activité acidifiante d'un certain nombre de cultures pures et des cultures mixtes correspondantes. Dans ce cas, les cultures étaient divisées en deux séries : après ensemencement, une série étant soumise au chauffage avant incubation, tandis que l'autre série, considérée comme témoin, était incubée aussitôt, dans les conditions habituelles.

Préparation des filtrats de culture. Nous avons utilisé la méthode décrite par Bautista et al. [3]. La culture pure étudiée, au terme de la période d'incubation choisie, était centrifugée à $8000 \mathrm{t} / \mathrm{mn}$ pendant $1 \mathrm{~h}$ à $4^{\circ} \mathrm{C}$. Le $\mathrm{pH}$ du surnageant était ajusté à 7,0 et son volume ramené au volume initial de la culture à l'aide d'eau distillée. Le surnageant était ensuite stérilisé par passage sur filtre Seitz. S'il

* Un degré Dornic correspond à 0,1 g d'acide lactique par litre de lait. 
n'était pas utilisé immédiatement, le surnageant était conservé à l'état congelé à $-30^{\circ} \mathrm{C}$.

RECHERCHE DE L'EFFET STIMULANT DES FILTRATS DE CULTURE ET DES DIVERSES SUBSTANCES ÉTUdiÉES. Pour mettre en évidence l'effet stimulant éventuel d'un filtrat de culture sur une souche bactérienne déterminée, $1 \mathrm{ml}$ du filtrat étudié était ajouté à $9 \mathrm{ml}$ de lait ensemencé avec cette souche. On préparait une culture témoin, en ajoutant à la place du filtrat, $1 \mathrm{ml}$ de lactosérum obtenu par acidification du lait à $\mathrm{pH}$ 4,6 à l'aide d'acide lactique et ajusté ensuite à $\mathrm{pH} 7,0$.

Pour rechercher l'effet stimulant éventuel d'une substance déterminée on ajoutait $1 \mathrm{ml}$ de la solution de cette substance $(1 \mathrm{ml}$ d'eau distillée stérile dans le cas de la culture témoin) à $9 \mathrm{ml}$ de lait ensemencé avec la souche étudiée. Les concentrations des solutions des diverses substances étudiées seront précisées dans les figures ou tableaux correspondants. Dans le cas des acides aminés, nous avons généralement utilisé les concentrations préconisées par Pette et Lolkema [13].

On comparaît les quantités d'acide produites par les différentes cultures et la culture témoin, après une durée d'incubation déterminée.

RECHERCHE DE L'EFFET STIMULANT DE Str. thermophilus SUR LES LACTOBACILLES THERMOPHILES. Nous avons utilisé la méthode décrite par Galesloot et al. [4]. La culture de Str. thermophilus, sur lait chauffé à $80^{\circ} \mathrm{C}$ pendant $30 \mathrm{mn}$, était effectuée en anaérobiose, sous azote. Quand le $\mathrm{pH}$ atteignait 5,7-6,1, la culture était ajustée à $\mathrm{pH}$ 6,6, puis pasteurisée à $80^{\circ} \mathrm{C}$ pendant $10 \mathrm{mn}$. Elle était ensuite ensemencée avec le lactobacille. Une culture témoin du même lactobacille était effectuée sur du lait qui avait été acidifié à l'aide d'acide lactique jusqu'à un $\mathrm{pH}$ égal à celui de la culture du streptocoque, puis neutralisé et pasteurisé. On comparaît les quantités d'acide produites par les deux cultures du lactobacille.

\section{Résultats}

1) INTERACTIONS ENTRE Str, thermophilus ET LES LACTOBACILLES THERMOPHILES

\section{Sur lait autoclavé}

La production d'acide de cultures pures de Str. thermophilus et d'un lactobacille thermophile, et d'une culture associant un lactobacille à Str. thermophilus est représentée, à titre d'exemple, sur la figure 1. Un effet synergique notable peut être généralement mis en évidence pendant la première phase de l'incubation. En effet, la quantité d'acide produite par la culture mixte est, pendant cette période, nettement supérieure à la somme des quantités d'acide produites par chacune des deux souches en culture pure. Un effet 


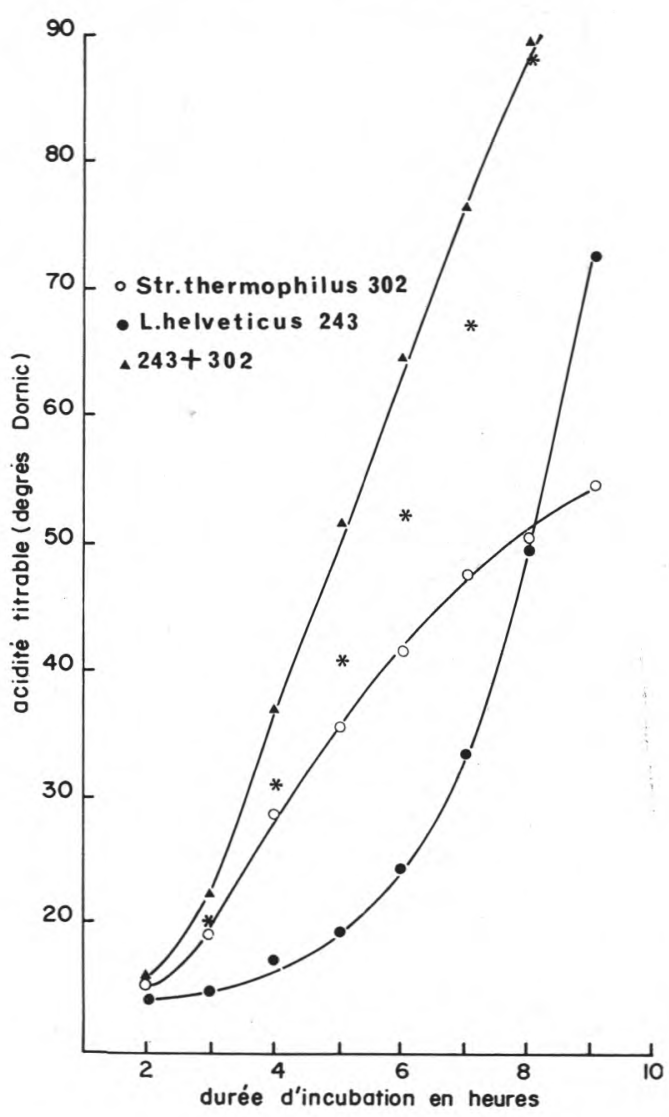

fig. 1

Production d'acide de Str. thermophilus 302 et de L. helveticus 243 , en culture pure et en mélange, dans du lait autoclavé $\left(110^{\circ} \mathrm{C}, 10 \mathrm{mn}\right)$.

Inoculum : 0,1 p. 100 ; incubation à $42^{\circ} \mathrm{C}$.

* Somme des quantités d'acide produites par chacune des deux cultures pures.

analogue a été observé avec chacune des souches de Str. thermophilus étudiées, associée à l'une quelconque des 14 souches de lactobacilles utilisées : L. helveticus (6 souches), L. jugurti (3 souches), L. bulgaricus (2 souches), L. lactis (3 souches).

Lorsqu'on ajoute un filtrat de culture de lactobacille à une culture sur lait autoclavé de Str. thermophilus, on obtient un effet 


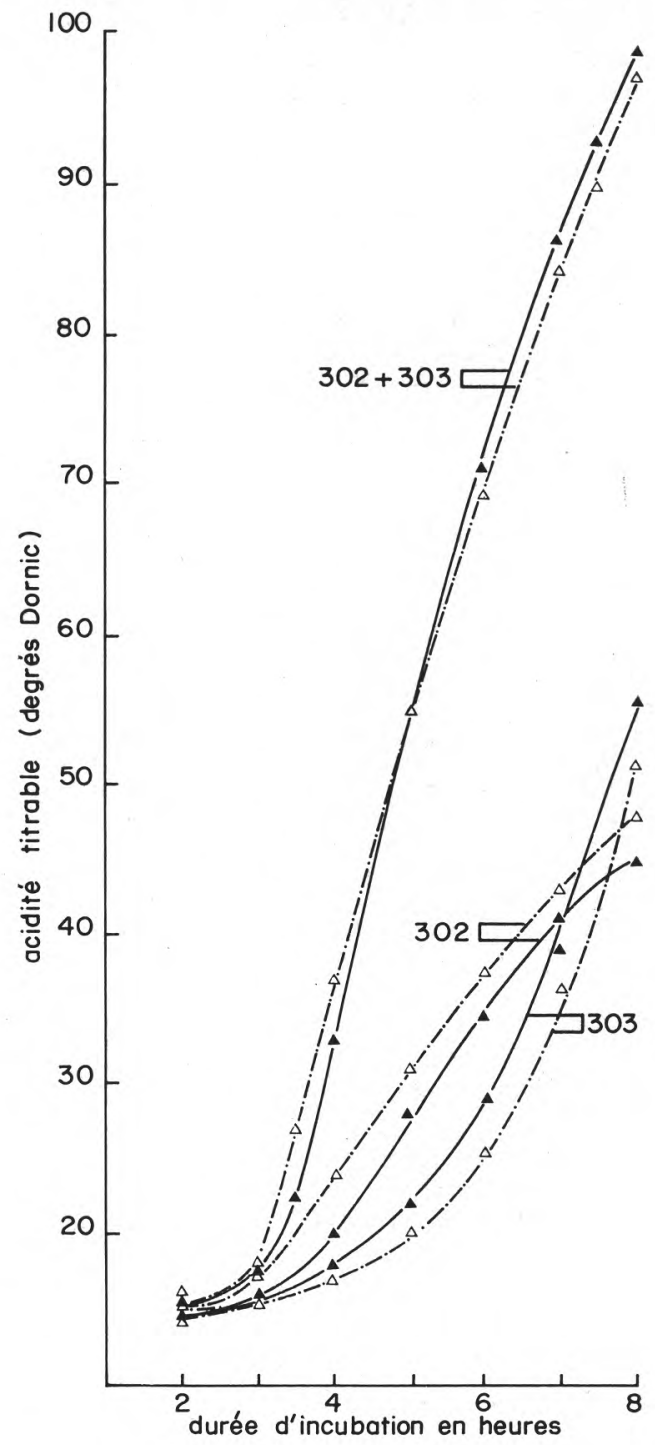

fig. 2

Production d'acide de Str. thermophilus 302 et de L. helveticus 303 , en culture pure et en mélange, avec ou sans chauffage préalable.

$\triangle$-.-. $\triangle$ Cultures non chauffées.

$\Delta-\mathbf{\Delta}$ Cultures chauffées $1 \mathrm{~h}$ à $54^{\circ} \mathrm{C}$ avant l'incubation. Lait autoclavé à $110^{\circ} \mathrm{C}, 10 \mathrm{mn}$; inoculum : $0,1 \mathrm{p} .100$; incubation à $42^{\circ} \mathrm{C}$. 


\section{TABLEAU 1}

Action des filtrats de culture de lactobacilles sur la production d'acide de Str. thermophilus dans du lait autoclavé $\left(110^{\circ} \mathrm{C}, 10 \mathrm{mn}\right)$

\begin{tabular}{|c|c|c|c|c|c|c|c|}
\hline \multirow{2}{*}{$\begin{array}{c}\text { Souches de } \\
\text { Str. thermophilus }\end{array}$} & \multicolumn{6}{|c|}{ Filtrats de culture des souches de lactobacilles } & \multirow{2}{*}{ Témoin } \\
\hline & $\begin{array}{c}\text { L. helveticus } \\
303\end{array}$ & $\begin{array}{l}\text { L. helveticus } \\
32\end{array}$ & $\begin{array}{l}\text { L. helveticus } \\
241\end{array}$ & $\begin{array}{l}\text { L. lactis } \\
239\end{array}$ & $\begin{array}{l}\text { L. lactis } \\
311\end{array}$ & $\begin{array}{c}\text { L. bulgaricus } \\
36\end{array}$ & \\
\hline 302 & $\begin{array}{c}53^{*} \\
(+10)^{* *}\end{array}$ & $\begin{array}{c}52 \\
(+9)\end{array}$ & $\begin{array}{c}51 \\
(+8)\end{array}$ & $\begin{array}{c}56 \\
(+13)\end{array}$ & $\begin{array}{c}53 \\
(+10)\end{array}$ & $\begin{array}{l}50 \\
(+7)\end{array}$ & 43 \\
\hline 160 & $\begin{array}{c}53 \\
(+11)\end{array}$ & $\begin{array}{c}51 \\
(+9)\end{array}$ & $\begin{array}{c}51 \\
(+9)\end{array}$ & $\begin{array}{c}56 \\
(+14)\end{array}$ & $\begin{array}{c}53 \\
(+11)\end{array}$ & $\begin{array}{c}51 \\
(+9)\end{array}$ & 42 \\
\hline 21 & $\begin{array}{c}50 \\
(+22)\end{array}$ & $\begin{array}{c}45 \\
(+17)\end{array}$ & $\begin{array}{c}46 \\
(+18)\end{array}$ & $\begin{array}{c}49 \\
(+21)\end{array}$ & $\begin{array}{c}43 \\
(+15)\end{array}$ & $\begin{array}{c}41 \\
(+13)\end{array}$ & 28 \\
\hline
\end{tabular}

* Acidité titrable exprimée en degrés Dornic.

** Différence entre les mesures d'acidité titrable effectuées sur la culture additionnée du filtrat étudié et sur la culture témoin. Inoculum : 1 p. 100 ; filtrat ajouté : 10 p. 100 ; incubation ; 4 h 30 à $42^{\circ} \mathrm{C}$. 
stimulant sur l'activité acidifiante de chacune des trois souches de Str. thermophilus étudiées (tab. 1). Par contre, les filtrats de culture de Str. thermophilus n'exercent, comparativement, pas d'effet stimulant mesurable sur la production d'acide de différents lactobacilles (tab. 2).

\section{TABLEAU 2}

Action des filtrats de culture de Str. thermophilus sur la production d'acide des lactobacilles dans du lait autoclavé*

\begin{tabular}{|c|c|c|c|c|}
\hline \multirow{2}{*}{$\begin{array}{l}\text { Souches de } \\
\text { lactobacilles }\end{array}$} & \multicolumn{3}{|c|}{$\begin{array}{l}\text { Filtrats de culture des souches de } \\
\text { Str. thermophilus }\end{array}$} & \multirow{2}{*}{ Témoin } \\
\hline & 302 & 160 & 21 & \\
\hline L. helveticus 303 & $\begin{array}{l}31 \\
(0)\end{array}$ & $\begin{array}{c}32 \\
(+1)\end{array}$ & $\begin{array}{l}31 \\
(0)\end{array}$ & 31 \\
\hline L. helveticus 32 & $\begin{array}{c}33 \\
(+1)\end{array}$ & $\begin{array}{l}32 \\
(0)\end{array}$ & $\begin{array}{l}33 \\
(+1)\end{array}$ & 32 \\
\hline L. helveticus 241 & $\begin{array}{l}27 \\
(0)\end{array}$ & $\begin{array}{l}27 \\
(0)\end{array}$ & $\begin{array}{l}27 \\
(0)\end{array}$ & 27 \\
\hline L. lactis 239 & $\begin{array}{l}20 \\
(0)\end{array}$ & $\begin{array}{l}20 \\
(0)\end{array}$ & $\begin{array}{c}21 \\
(+1)\end{array}$ & 20 \\
\hline L. lactis 311 & $\begin{array}{c}33 \\
(+2)\end{array}$ & - & $\begin{array}{c}33 \\
(+2)\end{array}$ & 31 \\
\hline L. bulgaricus 60 & - & $\begin{array}{l}32 \\
(0)\end{array}$ & - & 32 \\
\hline L. bulgaricus 322 & - & $\begin{array}{l}25 \\
(0)\end{array}$ & - & 25 \\
\hline
\end{tabular}

* Légende : Voir tab. 1.

Lorsqu'on soumet les différentes cultures, pures ou associées, à un traitement thermique de $1 \mathrm{~h}$ à $54^{\circ} \mathrm{C}$ avant incubation, on obtient des courbes d'acidification analogues à celles présentées sur la figure 2. On remarque que les courbes d'acidification de la culture mixte témoin et de la culture mixte chauffée sont peu différenciables; la culture mixte chauffée démarre un peu plus lentement que la culture mixte témoin, puis acidifie ensuite plus rapidement que celle-ci. Dans le cas des cultures pures chauffées, l'acidification de 
Str. thermophilus est sensiblement retardée, alors que celle de $L$. helveticus est légèrement stimulée. Il semble donc que le traitement thermique n'exerce un effet défavorable que vis-à-vis de Str. thermophilus. Il n'exerce pas d'effet marqué sur l'activité acidifiante de la culture mixte.

\section{$2^{\circ}$ Sur lait chauffé à $80^{\circ} \mathrm{C}$ pendant $30 \mathrm{mn}$}

Dans le cas des cultures mixtes sur lait chauffé à $80^{\circ} \mathrm{C}$ pendant $30 \mathrm{mn}$, on observe aussi un effet synergique marqué sur la production d'acide, lorsqu'on associe Str. thermophilus à un lactobacille

\section{TABLEAU 3}

Production d'acide des lactobacilles dans du lait chauffé $30 \mathrm{mn}$ à $80^{\circ} \mathrm{C}$ et soumis à une culture préalable de Str. thermophilus (a)

\begin{tabular}{|c|c|c|c|c|c|}
\hline \multirow{2}{*}{$\begin{array}{l}\text { Souches de } \\
\text { latobacilles }\end{array}$} & \multicolumn{4}{|c|}{ Cultures de Str. thermophilus } & \multirow{2}{*}{ Témoin } \\
\hline & Sts (d) & 21 & 302 & 160 & \\
\hline L. bulgaricus $\mathrm{Ib}(\mathrm{d})$ & $\begin{array}{c}55 \text { (b) } \\
(+22)(c)\end{array}$ & $\begin{array}{c}58 \\
(+25)\end{array}$ & $\begin{array}{c}51 \\
(+18)\end{array}$ & $\begin{array}{c}35 \\
(+2)\end{array}$ & 33 \\
\hline L. bulgaricus 36 & $\begin{array}{c}57 \\
(+19)\end{array}$ & $\begin{array}{c}54 \\
(+16)\end{array}$ & $\begin{array}{c}53 \\
(+15)\end{array}$ & $\begin{array}{c}39 \\
(+1)\end{array}$ & 38 \\
\hline L. lactis 69 & $\begin{array}{c}51 \\
(+21)\end{array}$ & $\begin{array}{c}44 \\
(+14)\end{array}$ & $\begin{array}{c}48 \\
(+18)\end{array}$ & $\begin{array}{l}30 \\
(0)\end{array}$ & 30 \\
\hline L. helveticus 303 & $\begin{array}{c}35 \\
(+4)\end{array}$ & $\begin{array}{c}34 \\
(+3)\end{array}$ & $\begin{array}{l}30 \\
(-1)\end{array}$ & $\begin{array}{l}28 \\
(-3)\end{array}$ & 31 \\
\hline L. helveticus 32 & $\begin{array}{c}35 \\
(+1)\end{array}$ & $\begin{array}{c}38 \\
(+4)\end{array}$ & $\begin{array}{c}32 \\
(-2)\end{array}$ & $\begin{array}{c}36 \\
(+2)\end{array}$ & 34 \\
\hline L. helveticus 241 & $\begin{array}{c}38 \\
(+5)\end{array}$ & $\begin{array}{c}39 \\
(+6)\end{array}$ & $\begin{array}{c}36 \\
(+3)\end{array}$ & $\begin{array}{c}35 \\
(+2)\end{array}$ & 33 \\
\hline L. jugurti 248 & $\begin{array}{c}35 \\
(+4)\end{array}$ & $\begin{array}{c}36 \\
(+5)\end{array}$ & $\begin{array}{c}35 \\
(+4)\end{array}$ & $\begin{array}{l}30 \\
(-1)\end{array}$ & 31 \\
\hline
\end{tabular}

(a) Ensemencement préalable de Str. thermophilus (inoculum : 2,5 p. 100) et incubation sous azote à $45^{\circ} \mathrm{C}$ jusqu'à $\mathrm{pH}$ 5,7-6,1, puis neutralisation à $\mathrm{pH}$ 6,6 et pasteurisation $\left(80^{\circ} \mathrm{C}, 10 \mathrm{mn}\right)$, enfin ensemencement du lactobacille (inoculum : 1 p. 100) et incubation $4 \mathrm{~h}$ à $45^{\circ} \mathrm{C}$.

(b) Acidité titrable exprimée en degrés Dornic.

(c) Différence entre les mesures d'acidité titrable effectuées sur la culture étudiée et sur la culture témoin.

(d) Les souches Sts et Ib nous ont été aimablement envoyées par le Dr Th. Galesloot. 
thermophile. Les filtrats de culture de lactobacilles exercent une action stimulante sur l'activité acidifiante des cultures de Str. thermophilus ; cette action est tout à fait comparable à celle que l'on obtient en utilisant du lait autoclavé.

Lorsqu'inversement on étudie l'influence des filtrats de culture de Str. thermophilus sur les lactobacilles, aucun effet stimulant n'apparaît. Toutefois, en opérant dans les conditions expérimentales décrites par Galesloot et al. [4] (voir Méthodes), il nous a été pos-

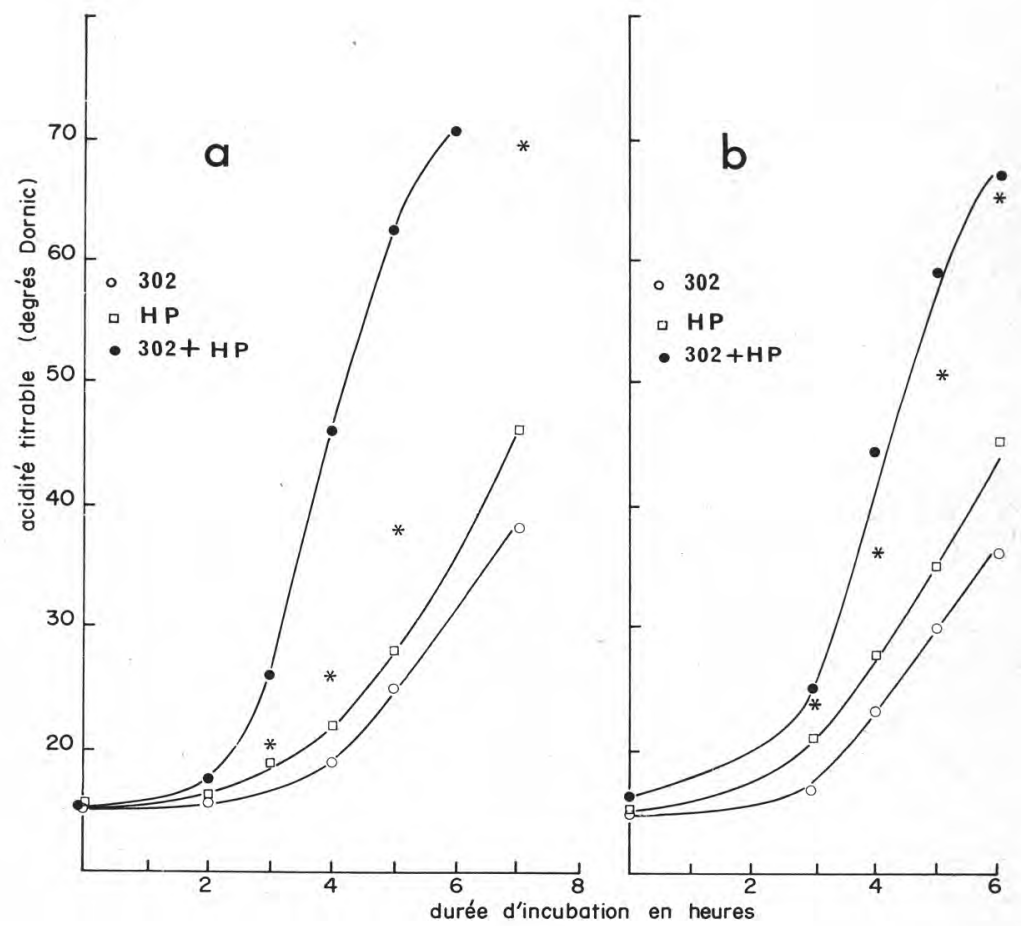

fig. 3

Production d'acide de Str. thermophilus 302 et de Str. cremoris $\mathrm{HP}$, en culture pure et en mélange, dans du lait chauffé $30 \mathrm{mn}$ à $80^{\circ} \mathrm{C}$.

a: Ensemencement simultané des deux souches ; inoculum : 1 p. 100 ; incubation à $37^{\circ} \mathrm{C}$.

b : Ensemencement préalable de Str. cremoris HP (inoculum : $0,1 \mathrm{p}$. 100) et incubation de $16 \mathrm{~h}$ à $13^{\circ} \mathrm{C}$, puis ensemencement de Str. thermophilus 302 (inoculum : 1 p. 100) et incubation à $37^{\circ} \mathrm{C}$.

* Somme des quantités d'acide produites par chacune des deux cultures pures. 
sible de mettre en évidence un effet stimulant marqué de deux des trois souches étudiées (Str. thermophilus 21 et 302) sur l'activité acidifiante de $L$. bulgaricus et de L. lactis. Comme le montre le tableau 3, l'effet stimulant observé sur L. bulgaricus 36 et sur L. lactis 69 est comparable à celui que Galesloot et al. [4] ont obtenu avec les souches Str. thermophilus Sts et L. bulgaricus Ib. Par contre, dans les mêmes conditions, l'effet stimulant des souches 21, 302 et Sts sur les différentes cultures de $L$. helveticus et de $L$. jugurti apparaît moins régulièrement ; de plus, cet effet est moins net, lorsqu'il se manifeste. On remarquera enfin que la souche Str. thermophilus 160 paraît totalement inactive.

Par ailleurs, il est intéressant de noter ici que les souches étudiées appartenant au groupe de L. helveticus - L. jugurti présentaient généralement une activité acidifiante comparable dans le lait autoclavé et dans le lait chauffé à $80^{\circ} \mathrm{C}$ pendant $30 \mathrm{mn}$. Nous avons par contre vérifié que les souches appartenant au groupe de L. lactis $L$. bulgaricus se caractérisaient par une activité acidifiante nettement supérieure en culture sur lait autoclavé, comme l'avaient montré Auclair et Portmann [1, 2].

\section{TABLEAU 4}

Action des filtrats de culture de streptocoques lactiques mésophiles sur la production d'acide de Str. thermophilus dans du lait chauffé $30 \mathrm{mn}$ à $80^{\circ} \mathrm{C}$

\begin{tabular}{|c|c|c|c|c|c|}
\hline \multirow{2}{*}{$\begin{array}{c}\text { Souches de } \\
\text { Str. thermophilus }\end{array}$} & \multicolumn{4}{|c|}{$\begin{array}{l}\text { Filtrats de culture des souches de } \\
\text { streptocoques mésophiles }\end{array}$} & \multirow{2}{*}{ Témoin } \\
\hline & $\begin{array}{l}\text { Str. } \\
\text { lactis } \\
\text { C } 10\end{array}$ & $\begin{array}{l}\text { Str. } \\
\text { cremoris } \\
\text { KH }\end{array}$ & $\begin{array}{l}\text { Str. } \\
\text { cremoris } \\
\text { HP }\end{array}$ & $\begin{array}{l}\text { Str. } \\
\text { lactis } \\
261\end{array}$ & \\
\hline 302 & $\begin{array}{c}49^{*} \\
(+13)^{* *}\end{array}$ & $\begin{array}{c}53 \\
(+17)\end{array}$ & $\begin{array}{c}59 \\
(+23)\end{array}$ & $\begin{array}{c}47 \\
(+11)\end{array}$ & 36 \\
\hline 160 & $\begin{array}{c}48 \\
(+12)\end{array}$ & $\begin{array}{c}52 \\
(+16)\end{array}$ & $\begin{array}{c}59 \\
(+23)\end{array}$ & $\begin{array}{c}47 \\
(+11)\end{array}$ & 36 \\
\hline 21 & $\begin{array}{c}40 \\
(+15)\end{array}$ & $\begin{array}{c}50 \\
(+25)\end{array}$ & $\begin{array}{c}47 \\
(+22)\end{array}$ & $\begin{array}{c}35 \\
(+10)\end{array}$ & 25 \\
\hline
\end{tabular}

* Acidité titrable en degrés Dornic.

** Différence entre les mesures d'acidité titrable effectuées sur la culture additionnée du filtrat étudié et sur la culture témoin.

Inoculum : 1 p. 100 ; filtrat ajouté : 10 p. 100 ; incubation : $6 \mathrm{~h}$ à $42^{\circ} \mathrm{C}$. 
2) INTERACTIONS ENTRE Str. thermophilus ET LES STREPTOCOQUES LACTIQUES MÉSOPHILES

La figure 3 illustre les résultats obtenus lorsqu'on cultive, dans du lait chauffé à $80^{\circ} \mathrm{C}$ pendant $30 \mathrm{mn}$, Str. thermophilus et un streptocoque lactique mésophile, soit séparément, soit en association. Dans l'essai correspondant à la figure 3a, Str. thermophilus 302 et Str. cremoris HP étaient ensemencés simultanément et l'incubation était effectuée à $37^{\circ} \mathrm{C}$. Dans l'essai de la figure $3^{\mathrm{b}}$ le lait était ensemencé faiblement avec le streptocoque mésophile $(0,1$ p. 100$)$ et était soumis à une incubation préalable de $16 \mathrm{~h}$ à $13^{\circ} \mathrm{C}$, Str. thermophilus était alors inoculé et l'incubation était poursuivie à $37^{\circ} \mathrm{C}$. Dans les deux cas, l'association des deux germes se traduit par un effet synergique marqué sur la production d'acide.

Cet effet, résultant de l'association de Str. thermophilus à un streptocoque lactique mésophile, paraît être assez général. Comme le montre le tableau 4, les filtrats de culture de divers streptocoques lactiques mésophiles, ajoutés aux cultures de différentes souches de Str. thermophilus, exercent un effet stimulant particulièrement net. Par contre, l'effet stimulant des filtrats de culture de Str. thermophilus sur l'activité acidifiante des streptocoques lactiques mésophiles varie d'une combinaison de souches à une autre (tab. 5). Parfois il n'apparaît pas et lorsqu'il se manifeste il est généralement moins net que l'effet inverse.

\section{TABLEAU 5}

Action des filtrats de culture de Str. thermophilus sur la production d'acide de streptocoques lactiques mésophiles dans du lait chauffé $30 \mathrm{mn}$ à $80^{\circ} \mathrm{C}^{*}$

\begin{tabular}{c|c|c|c|c}
\hline \multirow{2}{*}{$\begin{array}{c}\text { Souches de streptocoques } \\
\text { lactiques mésophiles }\end{array}$} & \multicolumn{2}{|c|}{$\begin{array}{c}\text { Filtrats de culture des souches de } \\
\text { Str. thermophilus }\end{array}$} & \multirow{2}{*}{ Témoin } \\
\cline { 2 - 3 } Str. lactis C 10 & 302 & 160 & 21 & \\
\cline { 2 - 3 } Str. Lactis 261 & $\begin{array}{c}48 \\
(+7)\end{array}$ & $\begin{array}{c}47 \\
(+6)\end{array}$ & $\begin{array}{c}49 \\
(+8)\end{array}$ & 41 \\
Str. cremoris KH & $\begin{array}{c}44 \\
(+5)\end{array}$ & $\begin{array}{c}37 \\
(-2)\end{array}$ & $\begin{array}{c}42 \\
(+3)\end{array}$ & 39 \\
Str. cremoris HP & $\begin{array}{c}65 \\
(+4)\end{array}$ & $\begin{array}{c}64 \\
(+3)\end{array}$ & $\begin{array}{c}60 \\
(-1)\end{array}$ & 61 \\
$(+7)$ & $\begin{array}{c}50 \\
(+11)\end{array}$ & $\begin{array}{c}36 \\
(-3)\end{array}$ & 39 \\
\hline
\end{tabular}

* Légende : Voir tableau 4 ; incubation $6 \mathrm{~h}$ à $30^{\circ} \mathrm{C}$. 
3) INTERACTION ENTRE $L$. helveticus ET LES STREPTOCOQUES LACTIQUES MÉSOPHILES

En cultivant $L$. helveticus et un streptocoque lactique mésophile dans du lait chauffé $30 \mathrm{mn}$ à $80^{\circ} \mathrm{C}$, nous n'avons pas observé d'effet synergique, que les organismes aient été ensemencés simultanément, ou que l'un d'eux ait subi une incubation préalable (fig. 4).

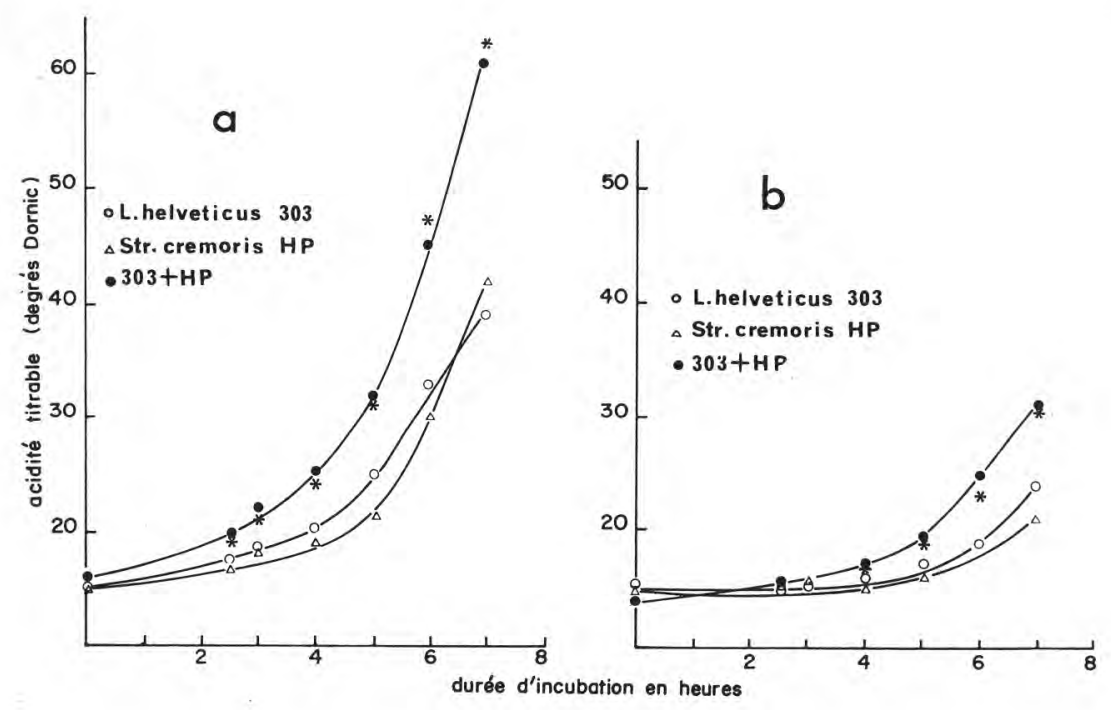

fig. 4

Production d'acide de L. helveticus 303 et de Str. cremoris HP, en culture pure et en mélange, dans du lait chauffé $30 \mathrm{mn}$ à $80^{\circ} \mathrm{C}$.

a: Ensemencement simultané des deux souches ; inoculum : 0,3 p. 100 ; incubation à $37^{\circ} \mathrm{C}$.

b : Ensemencement préalable de Str. cremoris HP (inoculum : 0,3 p. 100) et incubation de $16 \mathrm{~h}$ à $13^{\circ} \mathrm{C}$, puis ensemencement de L. helveticus 303 (inoculum: $1 \mathrm{p} .100$ ) et incubation à $37^{\circ} \mathrm{C}$.

* Somme des quantités d'acide produites par chacune des deux cultures pures.

Il ne nous a pas été possible de mettre en évidence un effet stimulant mesurable des filtrats de culture de streptocoques lactiques mésophiles sur les cultures de $L$. helveticus. Pour étudier inversement l'effet des filtrats de culture de $L$. helveticus sur les streptocoques lactiques mésophiles, nous avons utilisé les conditions habituelles d'incubation des cultures de streptocoques lactiques mésophiles $\left(30^{\circ} \mathrm{C}\right.$ pendant $\left.6 \mathrm{~h}\right)$. Dans ces conditions, les résultats obtenus 
varient selon les combinaisons de souches (tab. 6). Str. lactis C 10 et Str. cremoris KH ne sont stimulés par aucun filtrat, Str. lactis 261 est stimulé dans deux cas sur trois et seul Str. cremoris HP traduit un effet stimulant des trois filtrats étudiés.

\section{TABLEAU 6}

Action des filtrats de culture de L. helveticus sur la production d'acide des streptocoques lactiques mésophiles dans du lait chauffé $30 \mathrm{mn}$ à $80^{\circ} \mathrm{C}^{*}$

\begin{tabular}{c|c|c|c|c}
\hline \multirow{2}{*}{$\begin{array}{c}\text { Souche de streptocoques } \\
\text { lactiques mésophiles }\end{array}$} & \multicolumn{2}{|c|}{$\begin{array}{c}\text { Filtrats de culture des souches de } \\
\text { L. helveticus }\end{array}$} & \multirow{2}{*}{ Témoin } \\
\cline { 2 - 3 } & 303 & 32 & 241 & \\
\cline { 2 - 3 } Str. lactis C 10 & $\begin{array}{c}46 \\
(0)\end{array}$ & $\begin{array}{c}48 \\
(+2)\end{array}$ & $\begin{array}{c}48 \\
(+2)\end{array}$ & 46 \\
Str. cremoris KH & $\begin{array}{c}60 \\
(+2)\end{array}$ & $\begin{array}{c}60 \\
(+2)\end{array}$ & $\begin{array}{c}60 \\
(+2)\end{array}$ & 58 \\
Str. cremoris HP & $\begin{array}{c}51 \\
(+7)\end{array}$ & $\begin{array}{c}50 \\
(+6)\end{array}$ & $\begin{array}{c}52 \\
(+8)\end{array}$ & 44 \\
Str. lactis 261 & $\begin{array}{c}50 \\
(0)\end{array}$ & $\begin{array}{c}56 \\
(+6)\end{array}$ & $\begin{array}{c}55 \\
(+5)\end{array}$ & 50 \\
\hline
\end{tabular}

* Légende : Voir tableau 4 ; incubation $6 \mathrm{~h}$ à $30^{\circ} \mathrm{C}$.

4) INTERACTIONS ENTRE L. helveticus, Str. thermophilus ET LES STEPTOCOQUES LACTIQUES MÉSOPHILES

Les résultats précédents nous ont montré que, dans le lait chauffé $30 \mathrm{mn}$ à $80^{\circ} \mathrm{C}$, il était possible de mettre en évidence une stimulation réciproque entre Str. thermophilus et $L$. helveticus, une stimulation de Str. thermophilus par les streptocoques lactiques mésophiles, et éventuellement une stimulation de certaines souches de streptocoques lactiques mésophiles par Str. thermophilus ou par $L$. helveticus. Il en résulte que l'interprétation des courbes d'acidification de cultures mixtes où ces trois types de bactéries lactiques sont associées devient particulièrement complexe. A titre d'exemple la figure 5 montre les résultats obtenus avec de telles cultures. Dans un essai (fig. $5^{\text {a) }}$ les trois souches de bactéries lactiques étaient ensemencées simultanément. Dans l'autre essai (fig. $5^{\text {b) }}$ le strepto- 


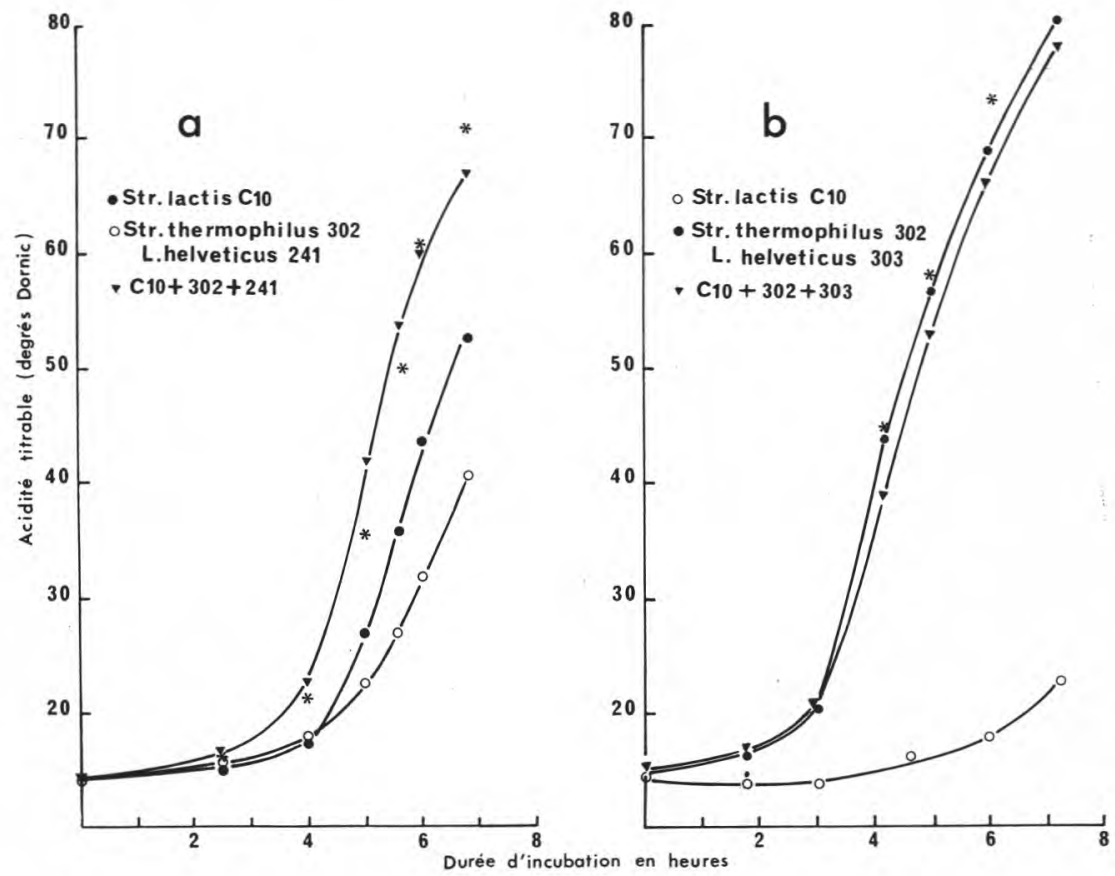

fig. 5

Production d'acide d'une culture mixte de Str. thermophilus, L. helveticus et Str. lactis C 10 dans du lait chauffé $30 \mathrm{mn}$ à $80^{\circ} \mathrm{C}$.

a : Ensemencement simultané des trois souches. Inoculum : 0,15 p. 100 (Str. thermophilus ou L. helveticus) et 0,3 p. 100 (Str. lactis) ; incubation à $37^{\circ} \mathrm{C}$.

b : Ensemencement préalable de Str. lactis (inoculum 0,001 p. 100) et incubation de $16 \mathrm{~h}$ à $13^{\circ} \mathrm{C}$, puis ensemencement de Str. thermophilus + L. helveticus (inoculum: 1 p. 100 pour chaque souche) et incubation à $37^{\circ} \mathrm{C}$.

* Somme des quantités d'acide produites par la culture mixte de Str. thermophilus et de L. helveticus et par la culture pure de Str. lactis.

coque lactique mésophile était ensemencé faiblement $(0,001$ p. 100), la veille de l'essai et le lait ainsi inoculé était incubé pendant $16 \mathrm{~h}$ à $13^{\circ} \mathrm{C}$. Les deux bactéries thermophiles étaient alors inoculées et l'incubation était poursuivie à $37^{\circ} \mathrm{C}$. On constate que l'action stimulante du streptocoque lactique mésophile sur la production d'acide de la culture mixte constituée par les deux bactéries thermophiles est peu marquée, lorsqu'elle peut être mise en évidence. Cette action apparaît généralement beaucoup moins nettement que celle qui résulte de l'association des deux bactéries thermophiles. 
Il en est de même lorsqu'on examine l'effet des filtrats de culture de différents streptocoques lactiques mésophiles sur les cultures associant deux à deux, différentes combinaisons de souches de Str. thermophilus et de L. helveticus (tab. 7). Un effet stimulant mesurable mais limité peut généralement être mis en évidence.

\section{$T A B L E A U 7$}

Action des filtrats de culture de streptocoques lactiques mésophiles sur la production d'acide de cultures mixtes composées de Str. thermophilus et de L. helveticus dans du lait chauffé $30 \mathrm{mn}$ à $80^{\circ} \mathrm{C}$

\begin{tabular}{|c|c|c|c|c|c|}
\hline \multirow{2}{*}{$\begin{array}{c}\text { Souches de } \\
\text { Str. thermophilus } \\
+ \\
\text { L. helveticus }\end{array}$} & \multicolumn{4}{|c|}{$\begin{array}{l}\text { Filtrats de culture de souches de } \\
\text { streptocoques mésophiles }\end{array}$} & \multirow{2}{*}{ Témoin } \\
\hline & $\begin{array}{l}\text { Str. } \\
\text { lactis } \\
\text { C. } 10\end{array}$ & $\begin{array}{l}\text { Str. } \\
\text { cremoris } \\
\mathrm{KH}\end{array}$ & $\begin{array}{c}\text { Str. } \\
\text { cremoris } \\
\text { HP }\end{array}$ & $\begin{array}{l}\text { Str. } \\
\text { lactis } \\
261\end{array}$ & \\
\hline $302+303$ & $\begin{array}{l}72^{*} \\
(+4)^{* *}\end{array}$ & $\begin{array}{c}74 \\
(+6)\end{array}$ & $\begin{array}{l}70 \\
(+2)\end{array}$ & $\left(\begin{array}{l}67 \\
(-1)\end{array}\right.$ & 68 \\
\hline $160+303$ & $\begin{array}{c}72 \\
(+4)\end{array}$ & $\begin{array}{l}74 \\
(+6)\end{array}$ & $\begin{array}{c}71 \\
(+3)\end{array}$ & $\begin{array}{c}71 \\
(+3)\end{array}$ & 68 \\
\hline $21+303$ & $\begin{array}{c}70 \\
(+12)\end{array}$ & $\begin{array}{c}68 \\
(+10)\end{array}$ & $\begin{array}{c}68 \\
(+10)\end{array}$ & $\begin{array}{c}70 \\
(+12)\end{array}$ & 58 \\
\hline $302+241$ & $\begin{array}{c}73 \\
(+4)\end{array}$ & $\begin{array}{l}75 \\
(+6)\end{array}$ & $\begin{array}{c}73 \\
(+4)\end{array}$ & $\begin{array}{c}72 \\
(+3)\end{array}$ & 69 \\
\hline $160+241$ & $\begin{array}{c}69 \\
(+4)\end{array}$ & $\begin{array}{l}72 \\
(+7)\end{array}$ & $\begin{array}{c}71 \\
(+6)\end{array}$ & $\begin{array}{l}67 \\
(+2)\end{array}$ & 65 \\
\hline $21+241$ & $\begin{array}{c}67 \\
(+2)\end{array}$ & $\begin{array}{c}71 \\
(+4)\end{array}$ & $\begin{array}{c}69 \\
(+4)\end{array}$ & $\begin{array}{c}68 \\
(+3)\end{array}$ & 65 \\
\hline $302+32$ & $\begin{array}{l}66 \\
(-2)\end{array}$ & $(-2)$ & $\begin{array}{c}70 \\
(+2)\end{array}$ & $\begin{array}{l}70 \\
(+2)\end{array}$ & 68 \\
\hline $160+32$ & $\begin{array}{l}69 \\
(+1)\end{array}$ & $\begin{array}{l}68 \\
(0)\end{array}$ & $\begin{array}{c}70 \\
(+2)\end{array}$ & $(-1)$ & 68 \\
\hline $21+32$ & $\begin{array}{c}72 \\
(+3)\end{array}$ & $\begin{array}{c}71 \\
(+2)\end{array}$ & $\begin{array}{c}70 \\
(+1)\end{array}$ & $\begin{array}{c}70 \\
(+1)\end{array}$ & 69 \\
\hline
\end{tabular}

* Acidité titrable exprimée en degrés Dornic.

** Différence entre les mesures d'acidité titrable effectuées sur la culture additionnée du filtrat étudié et sur la culture témoin.

Inoculum : 1 p. 100 ; filtrat ajouté : 10 p. 100 ; incubation : 4 h 30 à $42^{\circ} \mathrm{C}$. 
5) AdDition D'Acides AMinés AUX CUltures SUR LAIT DE Str. thermophilus

En ajoutant un seul acide aminé au lait, nous n'avons pu mettre en évidence d'effet stimulant marqué comparable à ceux que l'on observe dans les cultures de Str. thermophilus additionnées d'un filtrat de culture de lactobacille. Comme le montre le tableau 8 , seule l'histidine, parmi les trois acides aminés dont l'action nettement stimulante avait été observée par d'autres auteurs [3, 13], semble exercer un léger effet stimulant sur deux des trois souches étudiées. Cet effet est peu net lorsqu'on le compare à celui que l'on obtient avec un mélange complexe d'acides aminés tel que les " casamino acids vitamin free Difco ». Par ailleurs, certains acides aminés, en particulier la leucine ou l'isoleucine exercent un effet inhibiteur notable sur la production d'acide des cultures sur lait de Str, thermophilus.

\section{$T A B L E A U 8$}

Effet de l'addition de valine, de glycine ou d'histidine sur la production d'acide de Str. thermophilus dans du lait autoclavé $\left(110^{\circ} \mathrm{C}, 10 \mathrm{mn}\right)$

\begin{tabular}{|c|c|c|c|c|c|}
\hline $\begin{array}{l}\text { Souches de } \\
\text { Str. thermophilus }\end{array}$ & Valine & Glycine & Histidine & $\begin{array}{l}\text { Casamino } \\
\text { acids }\end{array}$ & Témoin \\
\hline 21 & $\begin{array}{c}24^{*} \\
(-2)^{* *}\end{array}$ & $\begin{array}{l}26 \\
(0)\end{array}$ & $\begin{array}{l}26 \\
(0)\end{array}$ & $\begin{array}{c}51 \\
(+25)\end{array}$ & 26 \\
\hline 160 & $\begin{array}{l}42 \\
(-1)\end{array}$ & $\begin{array}{l}42 \\
(-1)\end{array}$ & $\begin{array}{l}46 \\
(+3)\end{array}$ & $\begin{array}{c}58 \\
(+15)\end{array}$ & 43 \\
\hline 302 & $\begin{array}{l}37 \\
(-5)\end{array}$ & $\begin{array}{l}42 \\
(0)\end{array}$ & $\begin{array}{c}45 \\
(+3)\end{array}$ & $\begin{array}{c}54 \\
(+12)\end{array}$ & 42 \\
\hline
\end{tabular}

* Acidité titrable exprimée en degrés Dornic.

** Différence entre les mesures d'acidité titrable effectuées sur la culture additionnée de l'acide aminé étudié et sur la culture témoin.

Inoculum : 1 p. 100 ; incubation : 4 h 30 à $42^{\circ} \mathrm{C}$; concentrations (mg p. $100 \mathrm{ml}$ de lait) : valine, glycine, histidine : 50 ; «Casamino acids vitamin free Difco » : 20 .

L'étude de différentes combinaisons d'acides aminés nous a montré qu'un effet stimulant apparaissait lorsqu'on ajoutait au lait un mélange de trois acides aminés. Comme le montre le tableau 9 pour le lait chauffé à $80^{\circ} \mathrm{C}$ pendant $30 \mathrm{mn}$, le mélange leucine, isoleucine et valine stimule Str. thermophilus 21, alors que le 


\section{TABLEAU 9}

Effet de l'addition de deux combinaisons de trois acides aminés sur la production d'acide de Str. thermophilus dans du lait chauffé $30 \mathrm{mn}$ à $80^{\circ} \mathrm{C}$

\begin{tabular}{c|c|c|c}
\hline $\begin{array}{c}\text { Souches de } \\
\text { Str. thermophilus }\end{array}$ & $\begin{array}{c}\text { Leucine-Isoleucine } \\
\text { Valine }\end{array}$ & $\begin{array}{c}\text { Leucine-Isoleucine } \\
\text { Histidine }\end{array}$ & Témoin \\
\cline { 2 - 3 } 21 & $\begin{array}{c}33^{*} \\
(+12)^{* *}\end{array}$ & $\begin{array}{c}38 \\
(+17)\end{array}$ & 21 \\
30 & $\begin{array}{c}39 \\
(+9)\end{array}$ & 30 \\
302 & $(0)$ & $\begin{array}{c}40 \\
(+8)\end{array}$ & 32 \\
\hline
\end{tabular}

* Acidité titrable exprimée en degrés Dornic.

** Différence entre les mesures d'acidité titrable effectuées sur la culture additionnée du mélange d'acides aminés et sur la culture témoin.

Inoculum : 1 p. 100 ; incubation : 4 h 30 à $42^{\circ} \mathrm{C}$; concentrations (mg p. $100 \mathrm{ml}$ de lait) : leucine : 24 ; isoleucine : 28 ; valine : 14,4 ; histidine : 7,4 .

mélange leucine, valine et histidine exerce un effet stimulant sur chacune des trois souches étudiées, Str. thermophilus 21, 160 et 302. On obtient des résultats comparables en utilisant du lait autoclavé.

Les mélanges plus complexes d'acides aminés, s'ils renferment l'une des combinaisons leucine, isoleucine et valine ou leucine, valine et histidine exercent sur Str. thermophilus 21 un effet stimulant égal ou supérieur à celui de chacune de ces deux combinaisons. Les mélanges plus complexes d'acides aminés qui ne renferment pas ces combinaisons sont inactifs ou exercent au contraire un effet inhibiteur. Il en est de même, pour les souches 160 et 302, suivant que les mélanges plus complexes d'acides aminés contiennent ou ne contiennent pas la combinaison leucine, valine et histidine.

6) AdDITION D'ACIDE FORMIQUE OU D'ADÉNINE AUX CULTURES DE LACTOBACILLES SUR LAIT CHAUFFÉ A $80^{\circ} \mathrm{C}$

La production d'acide des lactobacilles thermophiles dans du lait chauffé pendant $30 \mathrm{mn}$ à $80^{\circ} \mathrm{C}$ et additionné d'acide formique ou d'adénine, permet de séparer les souches étudiées en deux groupes (tab. 10). Pour le premier groupe, comprenant les souches de L. bulgaricus et de L. lactis, l'acide formique et l'adénine exercent un effet stimulant net sur l'activité acidifiante de ces souches, comme 


\section{TABLEAU 10}

Effet de l'addition d'acide formique ou d'adénine sur la production d'acide des lactobacilles thermophiles, dans du lait chauffé $30 \mathrm{mn}$ à $80^{\circ} \mathrm{C}$

\begin{tabular}{|c|c|c|c|}
\hline Souches de lactobacilles & Formiate & Adénine & Témoin \\
\hline L. bulgaricus 36 & $\begin{array}{c}53^{*} \\
(+19)^{* \star}\end{array}$ & $\begin{array}{c}45 \\
(+11)\end{array}$ & 34 \\
\hline L. bulgaricus 60 & $\begin{array}{c}42 \\
(+10)\end{array}$ & $\begin{array}{c}48 \\
(+16)\end{array}$ & 32 \\
\hline L. lactis 69 & $\begin{array}{c}42 \\
(+13)\end{array}$ & $\begin{array}{c}41 \\
(+12)\end{array}$ & 29 \\
\hline L. lactis 311 & $\begin{array}{c}40 \\
(+10)\end{array}$ & $\begin{array}{c}43 \\
(+13)\end{array}$ & 30 \\
\hline L. lactis 239 & $\begin{array}{c}40 \\
(+10)\end{array}$ & $\begin{array}{c}41 \\
(+11)\end{array}$ & 30 \\
\hline L. helveticus 303 & $\begin{array}{c}33 \\
(+1)\end{array}$ & $\begin{array}{c}29 \\
(-3)\end{array}$ & 32 \\
\hline L. helveticus 32 & $\left(\begin{array}{l}31 \\
(-1)\end{array}\right.$ & $\begin{array}{l}30 \\
(-2)\end{array}$ & 32 \\
\hline L. helveticus 241 & $\begin{array}{c}32 \\
(+2)\end{array}$ & $\begin{array}{c}34 \\
(+4)\end{array}$ & 30 \\
\hline L. jugurti 248 & $\begin{array}{l}31 \\
(0)\end{array}$ & $\begin{array}{c}28 \\
(-3)\end{array}$ & 31 \\
\hline
\end{tabular}

* Acidité titrable exprimée en degrés Dornic.

** Différence entre les mesures de l'acidité titrable effectuées sur la culture additionnée de la substance étudiée et sur la culture témoin.

Inoculum : 1 p. 100 pour L. helveticus et $L$. jugurti, 2,5 p. 100 pour L. bulgaricus et L. lactis ; incubation $4 \mathrm{~h} 30$ à $42^{\circ} \mathrm{C}$; concentrations $(\mathrm{mg} \mathrm{p} .100 \mathrm{ml}$ de lait) : formiate de calcium : 14 ; adénine : 4.

le laissait prévoir le travail d'Auclair et Portmann [2]. Il n'en est pas de même pour les souches de L. helveticus et de L. jugurti qui constituent le second groupe. En effet, l'acide formique paraît sans action, alors que l'adénine exerce, suivant les souches, un léger effet stimulant ou au contraire un léger effet inhibiteur sur la production d'acide. Les variations de l'activité acidifiante sont généralement peu nettes et peu reproductibles, à la différence de celles que l'on obtient avec $L$. bulgaricus et $L$. lactis. 


\section{Discussion}

Les résultats précédents montrent que l'on obtient souvent une stimulation marquée de la production d'acide, en culture sur lait, lorsque l'on associe différentes bactéries lactiques. L'étude de l'effet des filtrats de culture pure nous a permis d'analyser les mécanismes de stimulation observés et de préciser les points suivants :

1) Les lactobacilles thermophiles et les streptocoques lactiques mésophiles exercent un effet stimulant marqué sur la production d'acide de Str. thermophilus.

Str. thermophilus est une bactérie lactique exigeante du point de vue nutritionnel, comme l'ont montré en particulier Guss et Delwiche [7] et Nurmikko [11]. Le lait ne constitue pas généralement un milieu de croissance optimal pour cette bactérie, en raison de sa teneur insuffisante en acides aminés et en peptides. Pour cette raison, on conçoit que l'addition de certains facteurs de croissance ou l'activité symbiotique de la bactérie associée à Str. thermophilus en culture mixte, puissent exercer un effet stimulant notable sur le développement et sur l'activité acidifiante de ce streptocoque thermophile, en culture sur lait.

La relation établie entre l'effet stimulant et la présence d'acides aminés libres s'appuie actuellement sur un certain nombre d'arguments expérimentaux. L'un des plus convaincants a été fourni par Bautista et al. [3], qui ont isolé d'un filtrat de culture de L. bulgaricus et identifié deux acides aminés stimulants, la glycine et l'histidine. Par ailleurs, Pette et Lolkema [13] avaient précédemment montré que l'addition de divers acides aminés au lait, six à onze suivant la saison, en particulier la valine, permettait d'obtenir un effet stimulant. Nous-mêmes avons montré que deux combinaisons de trois acides aminés, leucine-isoleucine-valine dans un cas et leucine-valine-histidine dans trois cas, sont nécessaires pour qu'un effet stimulant apparaisse nettement. Il est également bien connu que Str. thermophilus cultive beaucoup mieux dans le lait autoclavé que dans les laits chauffés à des températures inférieures à $100^{\circ} \mathrm{C}$, cet effet étant vraisemblablement lié à l'augmentation de l'azote non protéique dans le lait autoclavé [1].

Par ailleurs différents auteurs, en particulier Miller et Kandler $[9,10]$ ont montré que dans les cultures sur lait de streptocoques lactiques mésophiles et de lactobacilles thermophiles, on observait une augmentation quelquefois très importante de la teneur du lait en azote dialysable, incluant, surtout dans le cas des lactobacilles ( $L$. helveticus, $L$. jugurti, L. lactis, $L$. bulgaricus) un spectre d'acides aminés libres particulièrement riche.

En regard de ces données, les divergences relatives à la nature exacte des facteurs stimulants paraissent relativement mineures. 
Elles peuvent tout d'abord provenir de la composition du lait employé et du traitement thermique subi par ce lait, éventuellement des souches bactériennes étudiées. De plus il n'est pas certain que l'on reproduise fidèlement l'effet symbiotique de la culture mixte, lorsqu'on étudie l'effet d'un filtrat de culture de l'une des souches sur l'autre souche ou lorsqu'on cherche à mettre en évidence, par analogie, l'effet stimulant de différents acides aminés. Une telle méthode suscite en effet, dans le cas précis des acides aminés, un certain nombre de difficultés, comme le montre la discussion approfondie de Guirard et Snell [6].

2) Str. thermophilus peut exercer un effet stimulant marqué sur la production d'acide de certains lactobacilles, cet effet n'apparaissant pas toutefois dans les cultures sur lait autoclavé. Cette stimulation, mise en évidence dans le cas de $L$. bulgaricus par Galesloot et al. [4] et attribuée par ces mêmes auteurs à l'acide formique [18], apparaît également dans le cas de L. lactis. De plus, un effet stimulant comparable est obtenu en ajoutant au lait soit de l'acide formique, soit une base purique telle que l'adénine, l'acide formique intervenant vraisemblablement comme précurseur, au cours de la synthèse du noyau purique [8]. L'acide formique, lorsqu'il est formé dans le lait à la suite d'un traitement thermique suffisant, peut masquer l'action stimulante de Str. thermophilus. C'est le cas du lait autoclavé comme l'ont montré Auclair et Portmann [2]. Cet acide apparaît également dans les cultures de Str. thermophilus comme l'ont montré Platt et Foster [14] en utilisant un milieu de culture autre que le lait, ou Veringa et al. [18] avec du lait chauffé à $90^{\circ} \mathrm{C}$.

Il ne semble pas que Str. thermophitus exerce un effet stimulant comparable sur $L$. helveticus et $L$. jugurti, lactobacilles que l'on tend à réunir en une seule espèce occupant une position taxonomique relativement éloignée de $L$. bulgaricus et de L. Lactis $[5,17]$. De même, l'acide formique et l'adénine n'exercent pas d'effet stimulant net sur $L$. helveticus et $L$. jugurti.

L'effet stimulant de Str. thermophilus sur les lactobacilles thermophiles serait donc plus spécifique que l'effet stimulant inverse des lactobacilles sur Str. thermophilus.

3) L. helveticus et Str. thermophilus peuvent exercer un effet stimulant sur les streptocoques lactiques mésophiles. Toutefois nous n'avons pas réussi à mettre en évidence cet effet stimulant avec toutes les souches de streptocoques lactiques mésophiles étudiées. Lorsque cet effet se manifeste, il pourrait s'agir d'une action analogue à celle observée dans le cas de Str. thermophilus, action liée à la libération d'acides aminés ou de peptides. En effet, certaines souches de streptocoques lactiques sont également stimulées par ces composés, en culture sur lait [15].

D'un point de vue technologique, dans le cas des laits fermentés, en particulier dans le cas du yoghourt, il est maintenant bien établi 
que l'effet synergique observé dans les cultures mixtes de Str. thermophilus et de $L$. bulgaricus résulte d'un effet stimulant réciproque, le lait utilisé subissant généralement, à l'échelle industrielle, un traitement thermique inférieur à $100^{\circ} \mathrm{C}$.

Dans le cas des fromages à pâte cuite, on peut se demander dans quelle mesure il est possible de transposer en technologie les résultats obtenus au laboratoire, les conditions de culture (lait, caillé, température, etc.) étant difficilement comparables.

On peut toutefois supposer que la " maturation » du lait, en particulier dans le cas du lait pasteurisé et ensemencé ensuite avec un levain de streptocoques lactiques mésophiles, conduit à un effet stimulant favorable au développement ultérieur de Str, thermophilus, au cours de la fabrication et surtout de l'égouttage du fromage sous presse. Dans le cas du lait cru, la "maturation » est le fait d'une flore naturelle plus complexe, et il est vraisemblable que l'effet stimulant éventuel résultant de cette "maturation » est lié à la fois à l'activité de la flore lactique mésophile naturellement présente (ou ajoutée sous forme de levain) et à l'activité d'autres groupes bactériens. Par ailleurs il y a tout lieu de penser qu'au cours de la fabrication et de l'égouttage sous presse, les interactions synergiques intervenant entre les bactéries lactiques thermophiles présentes, Str. thermophilus, L. helveticus, L. lactis, s'exercent effectivement et contribuent, pour une grande part, à la bonne acidification et à l'égouttage correct du caillé. A cet égard, on remarquera en particulier que le traitement thermique que subit le caillé ne semble pas exercer d'action préjudiciable sur le développement et sur l'activité acidifiante des bactéries lactiques thermophiles.

\section{$R$ és u m é}

1) Les lactobacilles thermophiles (Lactobacillus bulgaricus, $L$. lactis, L. helveticus et $L$. jugurti) ainsi que les streptocoques lactiques mésophiles (Streptococcus lactis et Str. cremoris) stimulent la production d'acide de Str. thermophilus, dans le lait chauffé pendant $30 \mathrm{mn}$ à $80^{\circ} \mathrm{C}$ et dans le lait autoclavé. Cette stimulation résulte vraisemblablement de l'action protéolytique des germes stimulants sur les protéines du lait, car on peut obtenir un effet analogue en ajoutant au lait différentes combinaisons d'acides aminés. Les trois souches de Str. thermophilus étudiées étaient stimulées par le mélange leucine, valine et histidine, et l'une d'entre elles était également stimulée par le mélange leucine, isoleucine et valine.

2) L. lactis et L. bulgaricus sont stimulés par certaines souches de Str. thermophitus, dans le lait chauffé pendant $30 \mathrm{mn}$ à $80^{\circ} \mathrm{C}$. Toutefois, cette action ne s'observe pas lorsqu'on utilise du lait autoclavé. L'action de Str. thermophilus sur $L$. helveticus et $L$. jugurti varie selon les souches et est généralement peu marquée, lorsqu'elle se manifeste. Nous avons par ailleurs confirmé que l'acide formique 
et l'adénine exerçaient un effet stimulant marqué sur L. lactis et $L$. bulgaricus. Par contre l'action de ces deux composés sur L. helveticus et $L$. jugurti est généralement peu nette et varie d'une souche à une autre.

3) L. helveticus et Str. thermophilus stimulent la production d'acide de certaines souches de streptocoques lactiques mésophiles. Cet effet varie selon les combinaisons de souches étudiées.

4) Le rôle éventuel de ces effets symbiotiques, au cours de la fabrication des fromages à pâte cuite, est discuté.

\section{S u m m a r y}

Study of the interactions between various thermophilic and mesophilic lactic acid bacteria, in relation to the making of gruyere cheese

1) Thermophilic lactobacilli (Lactobacillus bulgaricus, L. helveticus and L. jugurti) as well as mesophilic lacti streptococci (Streptococcus lactis and Str. cremoris) stimulate the acid production of Str. thermophilus in milk heated at $80^{\circ} \mathrm{C}$ for $30 \mathrm{mn}$ and in autoclaved milk. This stimulation comes probably from the proteolytic action of the former organisms on milk proteins, as a similar effect may be observed by adding to milk various amino-acid combinations. The three strains of Str. thermophilus studied were stimulated by the mixture leucine + valine + histidine and one of these strains was also stimulated by the mixture leucine + isoleucine + valine.

2) L. lactis and L. bulgaricus are stimulated by certain strains of Str. thermophilus, in milk heated to $80^{\circ} \mathrm{C}$ for $30 \mathrm{mn}$. However this action can not be observed in autoclaved milk. The stimulatory action of Str. thermophilus on $L$. helveticus and $L$. jugurti varies with the strains and, when it does exist, is not very marked. We have confirmed that formic acid and adenine exert a definite stimulatory effect on $L$. lactis and $L$. bulgaricus. On the other hand, the action of these two compounds on L. helveticus and L. jugurti is, in general, not very marked, and it varies from strain to strain.

3) L. helveticus and Str. thermophilus stimulate the acide production of some strains of mesophilic lactic streptococci. This effect varies with the associations of strains studied.

4) The possible role of these symbiotic effects during the making of hard cheeses is discussed.

\section{Bibliographie}

[1] Auclair (J. E.) et Portmann (A.) (1955). - Influence du chauffage du lait sur le développement des bactéries. I. Croissance des bactéries lactiques dans des laits chauffés à des températures variables. Ann. Technol. agric., 4, 121-131. 
[2] Auclair (J. E.) et Portmann (A.) (1958). - Influence du chauffage du lait sur le développement des bactéries. II. Effet stimulant du lait autoclavé sur la croissance de Lactobacillus lactis. Ann. Technol. agric., 7, 129-150.

[3] Bautista (E. S.), Dahiya (R. S.) and Speck (M. L.) (1966). - Identification of compounds causing symbiotic growth of Streptococcus thermophilus and Lactobacillus bulgaricus in milk. J. Dairy Res., 33, 299-307.

[4] Galesloot (T. E.), Hassing (F.) and Veringa (H. A.) (1968). - Symbiosis in yoghurt. I. Stimulation of Lactobacillus bulgaricus by a factor produced by Streptococcus thermophilus. Neth. Milk Dairy J., 22, 50-63.

[5] Gasser (F.) and Mandel (M.) (1968). - Deoxyribonucleic acid base composition of the genus Lactobacillus. J. Bact., 96, 580-588.

[6] Guirard (B. M.) and SNell (E. E.) (1962). - Nutritional requirements of microorganisms dans "The Bacteria, vol. IV : The physiology of growth " (I. C. Gunsalus, R. Y. Stanier, ed.) p. 33-93, Academic Press, London and New-York.

[7] Guss (M. L.) and Delwiche (E. A.) (1953). - Streptococcus thermophilus. J. Bact., 67, 714-717.

[8] Magasanik (B.) (1962), - Biosynthesis of purine and pyrimidine nucleotides, dans "The Bacteria, vol. III : Biosynthesis» (I. C. Gunsalus, R. Y. Stanier, ed.) p. 295-334. Academic Press, New-York and London.

[9] Miller (I.) und Kandler (O.) (1967). - Eiweissabban und Anreicherung freier Aminosäuren durch Milchsäurebakterien in Milch. II. Die Anreicherung freier Aminosäuren durch Thermobakterien. Milchwiss., 22, 469-480.

[10] Mrller (I.) und Kandler (O.) (1967). - Eiweissabban und Anreicherung freier Aminosäuren durch Milchsäurebakterien in Milch. III. Die Anreicherung von freien Aminosäuren durch Streptobakterien und Streptokokken. Milchwiss., 22, 608-615.

[11] Nurmikкo (V.) (1964). - Growth chemistry of lactic acid bacteria. Department of Biochemistry, University of Turku, Turku, $206 \mathrm{p}$.

[12] Pette (J. W) and Lolkema (H.) (1950). - Yoghurt. I. Symbiose en antibiose in mengcultures van $L b$. bulgaricus en Sc. thermophilus. Neth. Milk Dairy J., 4, 197-208.

[13] Pette (J. W.) and Lolkema (H.) (1950). - Yoghurt. II. Groeifactoren voor Sc. thermophilus. Neth. Milk Dairy J., 4, 209-224.

[14] Platt (T. B.) and Foster (E. M.) (1958). - Products of glucose metabolism by homofermentative streptococci under anaerobic conditions. J. Bact., $75,453-459$.

[15] Reiter (B.) and Møller-Madsen (A.) (1963). - Reviews of the progress of dairy science. Section B. Cheese and butter starters. J. Dairy Res., 30, 419-456.

[16] RitTeR (P.) (1964). - Antibiose und Symbiose bei den Mikroorganismen und ihre Auswirkungen in der milchwirtschaftlichen Technik. Kieler Milchw. Forsch.-Ber., 16, 439-455.

[17] Sharpe (M. E.) (1962). - Taxonomy of the lactobacilli. Dairy Sci. Abstr., 24, 109-118.

[18] Veringa (H. A.), Galesloot (T. E.) and Davelaar (H.) (1968). - Symbiosis in yoghurt. II. Isolation and identification of a growth factor for Lactobacillus bulgaricus produced by Streptococcus thermophilus. Neth. Milk Dairy J., 22, 114-120. 